\title{
Scleroderma-associated cutaneous calcinosis: a remarkable regression post stem cell transplantation
}

\author{
Abuelmagd Abdalla $^{1}$ (D) Muhammad Khalid ${ }^{1} \cdot$ Qasim Ishaq $^{2} \cdot$ Suzanne Donnelly ${ }^{1}$ \\ Received: 10 August 2020 / Revised: 20 August 2020 / Accepted: 24 August 2020 / Published online: 26 August 2020 \\ (C) International League of Associations for Rheumatology (ILAR) 2020
}

\section{Indication}

We present a case of a woman with scleroderma with severe calcinosis that had regressed dramatically following stem cell transplant. This is a rare and novel finding with very few reports available in the literature.

\section{Case presentation}

A 49-year-old Caucasian female was diagnosed with anti$\mathrm{Scl} 70$ positive limited systemic sclerosis (SSc) with associated interstitial lung disease (ILD) at age 38. Her lung and skin disease had continued to worsen for the following years despite pulsed cyclophosphamide and maintenance of mycophenolate mofetil (MMF) and 5-10 mg prednisolone. Three years later, she started to develop calcinosis to her right wrist, which resulted in carpal tunnel-like symptoms secondary to median nerve compression by the large deposits of articular calcinosis (up to $2 \times 3 \mathrm{~cm}$ ) involving radiocarpal, intercarpal, and distal radio-ulnar joints in addition to the soft tissue around the distal radius and ulna (Fig. 1a).

The patient decided to proceed with autologous hematopoietic stem cell transplantation (HSCT) in the USA, which was carried out in 2016 at age 46,8 years after diagnosis. Three months after the transplant, her wrist

Abuelmagd Abdalla

dr_abuelmagd@icloud.com

1 Rheumatology Department, Mater Misericordiae University Hospital, Dublin 7, Ireland

2 Acute Medicine, Mater Misericordiae University Hospital, Dublin 7, Ireland calcinosis started to shrink, and eventually, her carpal tunnel symptoms disappeared, given the remarkable calcinosis regression (Fig. 1b). Her MMF and prednisolone were completely withdrawn 12 months post-transplant and remained on drug-free remission since. She is currently leading a healthy life with excellent quality.

\section{Discussion}

SSc is a heterogenous chronic progressive autoimmune disease characterized by small vessel vasculopathy, inflammation, and fibrosis with variable skin thickening (scleroderma) and internal organ involvement [1]. There is currently no available specific treatment for $\mathrm{SSc}$-associated calcinosis. Few reports had emerged regarding the successful use of rituximab as rescue therapy in refractory or severe SSc cases, with favourable outcomes in internal organs and skin disease, including calcinosis $[2,3]$.

Currently, there is no available data addressing SScassociated calcinosis as a primary or secondary outcome following HSCT. The current treatment of SSc-related calcinosis remains solely supportive. HSCT may serve as a promising therapeutic approach for $\mathrm{SSc}$-associated calcinosis. 
Fig. 1 Extensive wrist calcinosis 6 months pre HSCT (a) and 40 months post HSCT (b). Note the calcinosis regression (arrowed)

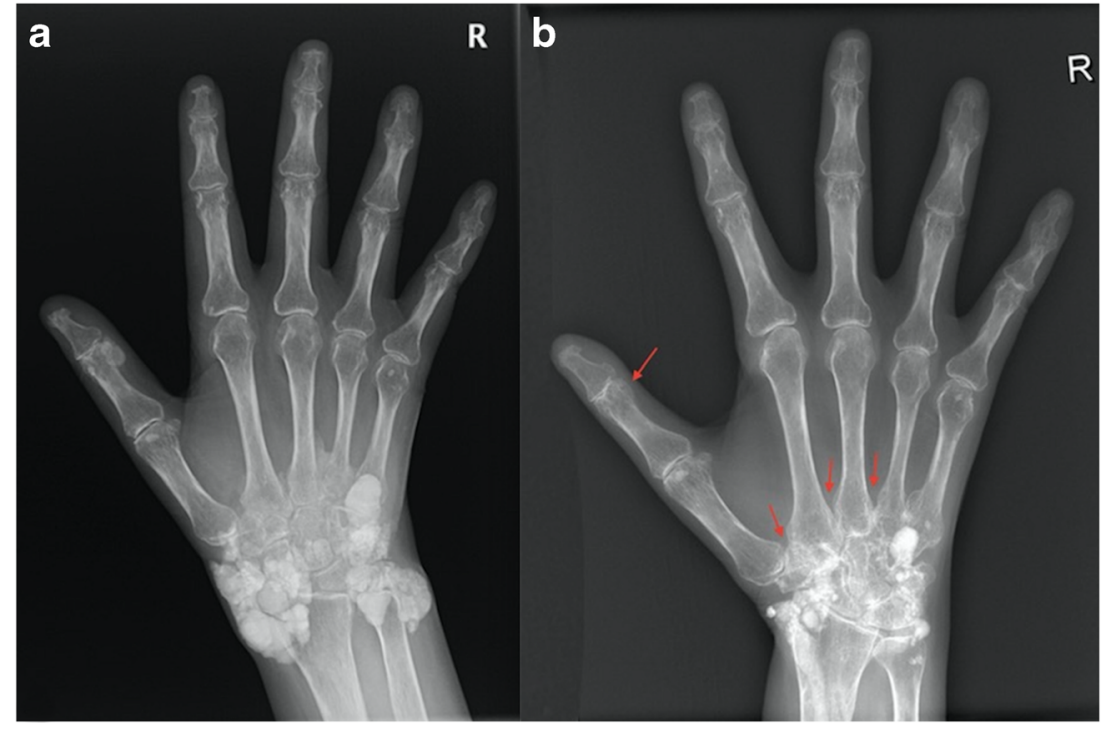

Acknowledgements The authors would like to thank the patient for consenting to share their story with the broader scientific community.

\section{Compliance with ethical standards}

\section{Disclosures None.}

\section{References}

1. Van Den Hoogen F, Khanna D, Fransen J, Johnson SR, Baron M, Tyndall A et al (2013) 2013 classification criteria for systemic sclerosis: an American College of Rheumatology/European League
Against Rheumatism collaborative initiative. Arthritis Rheum. 65(11):2737-2747

2. Daoussis D, Antonopoulos I, Liossis SNC, Yiannopoulos G, Andonopoulos AP (2012) Treatment of systemic sclerosisassociated calcinosis: a case report of rituximab-induced regression of CREST-related calcinosis and review of the literature. Semin Arthritis Rheum. 41(6):822-829

3. Narváez J, Pirola JP, LLuch J, Juarez P, Nolla JM, Valenzuela A (2019) Effectiveness and safety of rituximab for the treatment of refractory systemic sclerosis associated calcinosis: a case series and systematic review of the literature. Autoimmun Rev. 18(3):262-269. https://doi.org/10.1016/j.autrev.2018.10.006

Publisher's note Springer Nature remains neutral with regard to jurisdictional claims in published maps and institutional affiliations. 